\title{
The distribution of peptidase activity in the small intestine of sheep
}

\author{
BY R. I. RICHARDSON* AND A. R. P. JOUAN \\ Department of Agricultural Biochemistry and Nutrition, Faculty of Agriculture, The \\ University, Newcastle upon Tyne NE1 $7 R U$
}

(Received 21 February 1985 - Accepted 29 July 1985)

\begin{abstract}
1. The activity of peptidase enzyme(s) was measured in homogenates of mucosa taken at slaughter from sites along the length of sheep small intestine.

2. The activity of the homogenate towards six dipeptides showed a similar pattern of distribution for each substrate. Activity was lowest in the proximal duodenum, rising through the jejunum to peak in the mid-ileum and declining towards the terminal ileum. The distribution of activity towards two tripeptides was similar.

3. Studies using the inhibitor $p$-hydroxymercuribenzoate showed that the activity towards the dipeptides was mainly localized in the cytosol fraction, while that towards the tripeptides was evenly distributed between the cytosol and the brush-border and activity towards a tetrapeptide was mainly associated with the brush-border.

4. The results are discussed in relation to the site and mechanism of protein digestion and absorption in the ruminant small intestine.
\end{abstract}

It is clear from studies with non-ruminant species that a considerable proportion of digested protein is taken up from the digestive tract in the form of short-chain peptides which are then hydrolysed to their constituent amino acids at or in the gut wall (Adibi, 1971; Mathews, 1975). The enzyme activity towards di- and some tripeptides is mainly concentrated in the cytoplasm of the enterocyte, whilst virtually all the activity towards the longer-chain-length peptides is located on the brush-border membrane (Peters, 1970; Kim et al. 1972; Nicholson \& Peters, 1979; Sterchi \& Woodley, 1980a).

Whilst different sites along the intestine have been shown to be important for the digestion of protein and subsequent absorption of the end-products arising in sheep (Ben-Ghedalia et al. 1974; Tagari \& Bergman, 1978) and steers (McAllan, 1981), these conclusions derive from measurements of gross changes in gut contents along its length.

Differences in the rates of absorption of amino acids along the length of the small intestine of sheep have also been noted from studies both in vivo (Williams, 1969; Ben-Ghedalia et al. 1974; Tagari \& Bergman, 1978) and in vitro (Johns \& Bergen, 1973; Phillips et al. 1976).

Symons \& Jones (1966) measured the enzyme activity towards three dipeptide substrates in the high-speed supernatant fraction of homogenates of ovine small intestine and concluded that the soluble dipeptidase activity increases from proximal duodenum to mid-ileum and then declines towards the terminal ileum.

As the distribution of peptidase activity both along the length of the small intestine and between brush-border membrane and cytoplasm varies both with species and with substrate used, the present study was undertaken to examine more thoroughly the distribution of peptidase activity in the small intestine of sheep. The number of sites sampled was considerably increased compared with earlier studies as was the number of peptides employed. 


\section{MATERIALS AND METHODS \\ Source of intestines}

Intestines were obtained from a local abattoir from sheep killed by electrocution and subsequent severance of the blood vessels of the neck. The small intestines were removed as soon after death as possible, dissected free of the mesentery, care being taken to avoid undue stretching, and their lengths measured. Initially, a $100 \mathrm{~mm}$ sample of intestine was taken from sites $0 \cdot 02,4,12,28,60$ and $100 \%$ of the total length from the pylorus. Four sheep were sampled. The sites chosen corresponded to the sites of insertion of re-entrant cannulas in the experiments of Ben-Ghedalia et al. (1974). In a subsequent experiment, samples were taken at sites corresponding to $10 \%$ intervals along the measured length of the small intestine, beginning at a point $5 \%$ along the length of the intestine from the pylorus, ten samples being taken in all. Six sheep were sampled. The $100 \mathrm{~mm}$ samples were cut open, rinsed rapidly in ice-cold physiological saline $(9 \mathrm{~g}$ sodium chloride $/ 1)$, drained of excess liquid, transferred to individual plastic bags and transported on ice.

\section{Preparation of homogenates}

Homogenates were prepared by the method of McCarthy \& Kim (1973). The $100 \mathrm{~mm}$ segments were placed on a cooled ceramic tile, gently blotted and the mucosa scraped off with a microscope slide. The mucosa was homogenized with twelve hand-strokes of a Potter-Elvehjem homogenizer, in $8 \mathrm{ml}$ glycerol solution $(140 \mathrm{~g} / \mathrm{l})$. The homogenate was strained through a double layer of nylon bolting cloth $(61 \mu \mathrm{m}$ pore size; Henry Simon Ltd, Cheadle Hulme, Cheshire), divided into portions and stored frozen $\left(-20^{\circ}\right)$. Preliminary studies showed that less than $5 \%$ of activity was lost during frozen storage. Samples were only thawed once and then discarded.

\section{Chemicals}

All biochemicals were obtained from Sigma (Sigma Chemical Co. Ltd, Poole, Dorset). L-Amino acid oxidase $(E C$ 1.4.34.2) was type VI from Crotalus atrox venom and peroxidase $(E C 1.11 .1 .17)$ was type 1 from horse-radish.

\section{Assay method}

Peptidase activity was measured by the method of Nicholson \& Kim (1975). Substrates used were: glycyl-L-leucine (gly-leu), L-leucylglycine (leu-gly), L-leucyl-L-leucine (leu-leu), Lprolyl-L-leucine (pro-leu), L-methionylglycine (met-gly), glycyl-L-phenylalanine (gly-phe), L-phenylalanylglycylglycine (phe-gly-gly), L-leucyl-L-leucyl-L-leucine (leu-leu-leu) and Lphenylalanylglycylglycyl-L-phenylalanine (phe-gly-gly-phe).

In this linked assay the free amino acids, liberated by the presence of peptidase enzy $\cdot e(s)$ in the homogenate, are rapidly oxidized by L-amino acid oxidase, the resulting hydrogen peroxide being coupled by peroxidase to the oxidation of the chromogen, $o$-dianisidine. Of the amino acids in the peptides used, only L-leucine, L-methionine and L-phenylalanine are oxidized. A standard curve was prepared for each. Thus, the amount of the amino acid that was measured as being released from gly-leu, leu-gly, gly-phe, met-gly and pro-leu was a direct measure of the amount of dipeptide hydrolysed. For leu-leu the results were divided by two. With leu-leu-leu as substrate it was assumed that the products were L-leucine and L-leucyl-L-leucine. The tripeptidase would not have hydrolysed the dipeptide (Duomeng \& Maroux, 1979) and the concentration of dipeptide produced $(<0.1 \mathrm{~mm})$ would be too low to allow significant dipeptidase activity. For phe-gly-gly and phe-gly-gly-phe only the release of the $N$-terminal L-phenylalanine would be measured. 


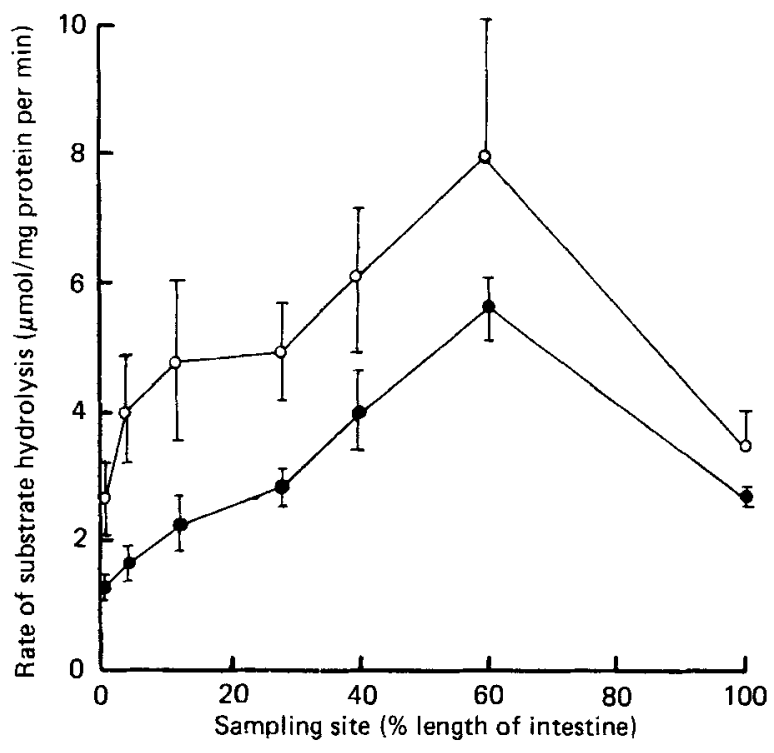

Fig. 1. The distribution of peptidase activity in homogenates of sheep intestinal mucosa from different sites along the length of the small intestine towards glycyl-L-leucine $(O)$, L-leucylglycine $(\Theta)$. Points are means with their standard errors, represented by vertical bars, for samples from four sheep.

\section{Assay procedure}

All reagents were dissolved in Tris-hydrochloric acid buffer $(0.5 \mathrm{M}, \mathrm{pH} 8 \cdot 0)$. A $0 \cdot 3 \mathrm{ml}$ portion of substrate ( $5 \mathrm{~mm}$ in the final reaction volume) was added to $0.6 \mathrm{ml} \mathrm{L}$-amino acid oxidase reagent (LAOR) (180 units L-amino acid oxidase, $20 \mathrm{mg}$ horse-radish peroxidase and $100 \mathrm{mg} o$-dianisidine $/ 1$ Tris- $\mathrm{HCl}$ buffer, $\mathrm{pH} 8.0$ ) in a $3 \mathrm{ml}$ test-tube and incubated at $37^{\circ}$ for $5 \mathrm{~min}$. The reaction was begun by the addition of $0.015 \mathrm{ml}$ of a suitably diluted homogenate. The reaction was stopped after $20 \mathrm{~min}$ by the addition of $0.45 \mathrm{ml}$ sulphuric acid $(9 \mathrm{M})$. The absorbance of the resultant purple colour was determined at $530 \mathrm{~nm}$ using a Pye Unicam Sp6 spectrophotometer $(10 \mathrm{~mm}$ light path). Homogenate and substrate blanks were taken through the same procedure. All assays were performed in duplicate. Continuous monitoring of the reactions was carried out using the same reagent volumes, without the addition of sulphuric acid, and at $440 \mathrm{~nm}$. Standard curves for the reacting amino acids in the peptide substrate were run simultaneously with the measurement of homogenate activity. The amino acid standard curve was in the range 0-120 nmol amino acid in the final reaction volume. Homogenates were diluted with glycerol solution so that no more than $100 \mathrm{nmol}$ amino acid were released in the $20 \mathrm{~min}$ incubation period. The linearity of the reaction with respect to time, substrate concentration and amount of protein present was established with homogenates from sheep small intestine.

\section{Determination of brush-border peptidase activity}

Heizer et al. (1972) have shown that $p$-hydroxymercuribenzoate (PHMB) will fully inhibit the soluble cytosol peptidase activity. Brush-border peptidase activity present in the homogenates was assessed by including PHMB in the LAOR to a final concentration of $0.5 \mathrm{~mm}$ in the reaction tube. 
(a)

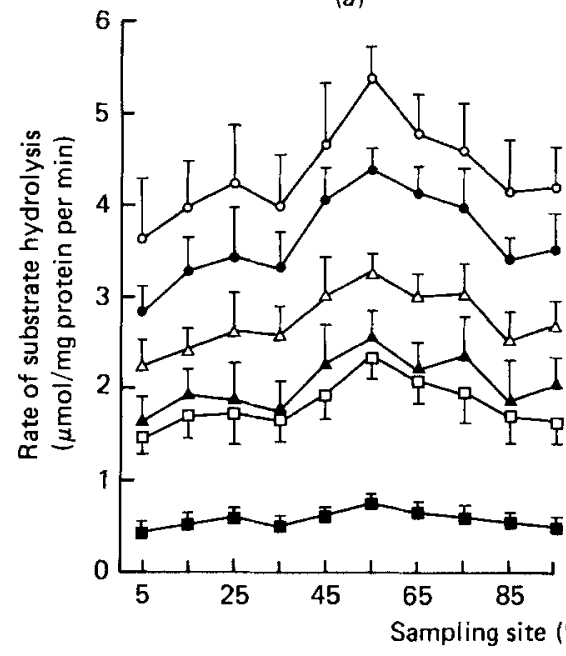

(b)

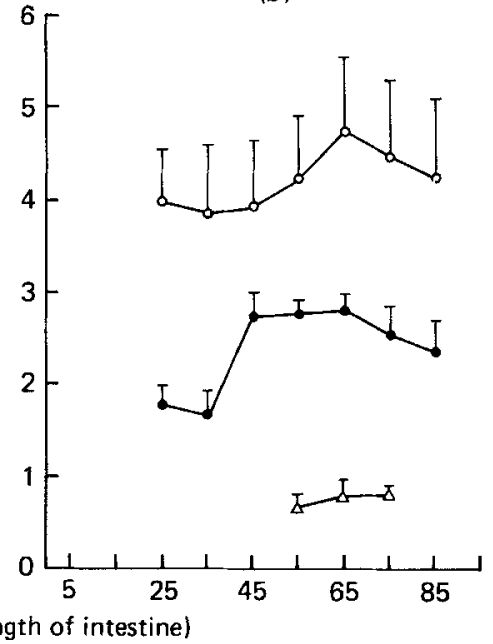

Fig. 2. The distribution of peptidase activity in homogenates of sheep intestinal mucosa taken from different sites along the length of the small intestine towards $(a)$ glycyl-L-leucine $(O)$, glycyl-L-phenylalanine ( $(\mathbf{)})$, L-methionylglycine $(\triangle)$, L-leucyl-L-leucine $(\boldsymbol{\Delta})$, L-leucylglycine $(\square)$, L-prolyl-L-leucine $(\boldsymbol{\square})$; (b) L-phenylalanylglycylglycine (O), L-leucyl-L-leuclyl-leucine (O), L-phenylalanylglycyiglycyl-L-phenylalanine $(\triangle)$. Points are means with their standard errors, represented by vertical bars, for samples from six sheep.

Table 1. Brush-border enzyme activity of sheep intestinal homogenates as a proportion of total intestinal activity

(Results are means with their standard errors for estimations performed using six sheep with samples taken at $25,35,45,55,65,75$ and $85 \%$ of the length of the intestine for di- and tripeptides and at 55 , 65 , and $75 \%$ of the length of the intestine for the tetrapeptide)

\begin{tabular}{|c|c|c|c|}
\hline \multirow[b]{2}{*}{ Substrate } & \multicolumn{2}{|c|}{$\begin{array}{l}\text { Proportion brush- } \\
\text { border activity }\end{array}$} & \multirow{2}{*}{$\begin{array}{l}\text { No. of } \\
\text { estimates }\end{array}$} \\
\hline & Mean & SE & \\
\hline Glycyl-L-phenylalanine & $0 \cdot 107$ & $0 \cdot 004$ & 42 \\
\hline L-Methionylglycine & $0 \cdot 257$ & $0 \cdot 009$ & 42 \\
\hline L-Leucyl-L-leucine & $0 \cdot 226$ & $0 \cdot 005$ & 42 \\
\hline L-Leucylglycine & $0 \cdot 141$ & $0 \cdot 013$ & 42 \\
\hline L-Phenylalanylglycylglycine & 0.413 & 0.011 & 42 \\
\hline L-Leucyl-L-leucyl-L-leucine & 0.647 & 0.017 & 42 \\
\hline L-Phenylalanylglycylglycyl-L-phenylalanine & 0.827 & 0.046 & 18 \\
\hline
\end{tabular}

\section{Centrifugation}

Soluble and particulate-bound enzymes were separated by the method of McCarthy \& Kim (1973), using a Beckman ultracentrifuge (model L-2). The supernatant fraction was used for kinetic studies.

\section{Protein determination}

Protein in the homogenates was determined by the modified Folin-Lowry method of Miller (1959). Bovine serum albumin, dissolved in glycerol (140 g/1), was used as standard. 
Table 2. Apparent $\mathrm{k}_{\mathrm{m}}$ values for the enzyme activity of the cytoplasmic fraction of sheep intestinal mucosa for five dipeptide substrates

\begin{tabular}{lll}
\hline & \multicolumn{2}{c}{ Apparent $k_{m}$ (mM) } \\
\cline { 2 - 4 } Substrate & $1^{*}$ & $2^{*}$ \\
\hline Glycycl-L-phenylalanine & 1.52 & 0.50 \\
L-Methionylglycine & 1.32 & 0.66 \\
L-Leucylglycine & 1.36 & 0.49 \\
L-Leucyl-L-leucine & 1.75 & 0.75 \\
L-Prolyl-L-leucine & 3.81 & - \\
\hline
\end{tabular}

* There was more than one $k_{m}$ for each substrate measured except for L-prolyl-L-leucine.

\section{RESULTS}

The distribution of peptidase activity along the small intestine

In the initial investigation, gly-leu and leu-gly were used as substrates. For both substrates the enzyme activity measured in the crude homogenates was low in the most proximal sample, rose to a plateau at $12-28 \%$ along the length of the small intestine, subsequently rose to a peak at $60 \%$ and declined thereafter (Fig. 1). In view of these results, samples were obtained from a further six sheep with an even distribution of sampling sites. The mean length of the six intestines was $20.6(\mathrm{SE} 0.7) \mathrm{m}$. The mean peptidase activities towards six dipeptide substrates at each of the ten sites are shown in Fig. 2(a). The values and distribution of activity with gly-leu and leu-gly as substrates are similar to those shown in Fig. 1. However, the absolute values in Fig. 1 are higher, mainly due to the values for one sheep being twice those of the rest. Activity rose in the first $35 \%$ of the tract, rising more sharply to a peak at $55 \%$ and then declined towards the terminal ileum. The distribution of activity was the same for all six substrates with highly significant correlations $(P<0.001)$ between the activity with any two substrates at all sites ( $r$ range $0.797-0.968, n 60)$. The distributions of activity against two tripeptides and a tetrapeptide are shown in Fig. $2(b)$.

\section{Distribution of activity between brush-border and cytoplasm}

An attempt was made to partition the measured activity towards the various substrates into that associated with the brush-border and that associated with the cytoplasm by use of the cytoplasmic peptidase inhibitor PHMB. Mean results for all sites examined are given in Table 1 . It can be seen that the majority of dipeptidase activity was cytoplasmic whilst that against tripeptides was more evenly distributed and that for the tetrapeptide was virtually all associated with the brush-border.

\section{Kinetics}

The apparent $k_{m}$ values for five dipeptide substrates measured in the high-speed supernatant fractions of the homogenates are shown in Table 2. When Lineweaver-Burk plots were produced for each substrate it was noted that, at high substrate concentrations, a line of greater slope than that with low substrate concentrations could be drawn. This is indicative of the presence of a second enzyme in the supernatant which has a lower substrate affinity. If this is the case then the two values quoted are only approximations of the true $k_{m}$ values (Dixon \& Webb, 1964). A similar alinearity using the substrates leu-gly and phe-gly has been noted by Fujita et al. (1972). 


\section{DISCUSSION}

When discussing the distribution of enzyme activity along the length of the small intestine it is important that the specific activity should reflect the total activity. It has been shown that there is no difference in the wet weight of ovine small intestine per unit length (Wahle et al. 1972) and that there is no difference in protein content per unit fresh weight of mucosa (Symons \& Jones, 1966). Thus, enzyme specific activity should reflect total activity as indeed was found to be the case when the distribution of dipeptidase activity was measured in the small intestine of four species (Das \& Radhakrishnan, 1974). Similarly, the distribution of $\gamma$-glutamyl transpeptidase in ovine small intestine was the same whether expressed in terms of protein content, $g$ per wet weight of tissue or per half a $100 \mathrm{~mm}$ segment (Baumrucker \& Davis, 1980).

The present results confirm in more detail the findings of Symons \& Jones (1966). The measured activity towards dipeptide substrates was low in the proximal duodenum but increased in the first $5 \%$ of the tract and was maintained at a moderate level between 5 and $35 \%$, an area corresponding approximately to the jejunum. Activity subsequently increased to a peak at $55 \%$, the mid-ileum, and thereafter declined towards the terminal ileum, although remaining higher than in the proximal duodenum. This distribution is essentially similar to that noted in the guinea-pig, pig, rat and rabbit (Robinson \& Shaw, 1960; Josefsson \& Lindberg, 1965; Das \& Radhakrishnan, 1974). It is different from that observed in the monkey where activity is consistently high in the first $60 \%$ of the tract and decreases thereafter (Das \& Radhakrishnan, 1974).

Measurement of peptidase activity towards various substrates in homogenates is a measure of both cytosolic and brush-border enzymes. The use of the cytosolic peptidase inhibitor, PHMB, confirmed that the distribution of enzyme activity in the small intestine of sheep (Table 1) is similar to that in single-stomached species (Nicholson \& Peters, 1979; Sterchi \& Woodley, 1980a). There was a gradual increase in brush-border activity towards dipeptides from jejunum to terminal ileum. This has also been noted for guinea-pig, rat, rabbit and monkey (Das \& Radhakrishnan, 1974) and may explain why the total homogenate activity towards dipeptides in the present study decreased more slowly towards the terminal ileum than in the studies of Das \& Radhakrishnan (1974) who measured dipeptidase activity in the isolated cytosol fraction.

The range of substrates studied is insufficient to give any indication as to which amino acid combinations might be the preferred substrates. Das \& Radhakrishnan (1973) have suggested that there is only one cytosol-enzyme responsible for the hydrolysis of glycylL-leucine in rats (their 'master' dipeptidase, which hydrolysed sixty-five of seventy-five dipeptides tested). They suggest that there may be four or five other dipeptidases including the imino and imido dipeptidases and possibly one or more enzymes responsible for the hydrolysis of glycylglycine. All of these enzymes and the di-, tri- and tetrapeptidases of the brush-border (another potential five or six enzymes (Sterchi \& Woodley, 1980b)), would have been measured in the crude homogenate. An attempt using starch gel electrophoresis to enumerate the number of enzymes present in the soluble fraction of the homogenate was only partially successful. When all the di- and tripeptides used in the present study were employed to stain the zymograms, several diffuse bands were obtained. This is consistent with studies in other species where zymograms have shown that peptidases occur in multiple forms with overlapping specificity (Dolly et al. 1971; Kim et al. 1972).

It is noteworthy that pro-leu was hydrolysed least rapidly; this dipeptide is probably not a substrate for the master dipeptidase and suggests the presence of a second dipeptidase in the homogenate. It is also suggested that there is one enzyme present in the cytosol of rabbit mucosa responsible for all the tripeptidase activity (Duomeng \& Maroux, 1979). 
Similarly, the apparent $k_{m}$ values for the dipeptides measured gives no indication of the total number of enzymes present in the soluble fraction, though suggesting the presence of at least two enzymes.

Ben-Ghedalia et al. (1974) used multiple cannulation of the sheep small intestine to study the hydrolysis and absorption of the nitrogenous fractions in that organ. Although the $\mathrm{pH}$ of the lumen contents did not reach a level which would give maximal proteolytic activity by the proteolytic enzymes until $15 \mathrm{~m}(60 \%)$ along the small intestine, the maximal activity of trypsin (EC 3.4.21.4), chymotrypsin (EC 3.4.21.1) and carboxypeptidase A (EC 3.4.17.1) measured either at the $\mathrm{pH}$ in situ or at optimum $\mathrm{pH}$ for these enzymes was at $7 \mathrm{~m}(28 \%)$ along the tract. Ben-Ghedalia et al. (1974) were able to to give an indication of the distribution of the total nitrogenous fraction between protein-bound, peptide-bound and free amino acids. There was considerable digestion of protein between 1 and $7 \mathrm{~m}$ and this proceeded faster than absorption, as peptide and free amino acid accumulated between 1 and $3 \mathrm{~m}$. The peptide fraction showed a net disappearance between 3 and $7 \mathrm{~m}$ with the greatest net disappearance between 7 and $15 \mathrm{~m}$ and little more beyond that point, whilst net disappearance of free amino acids only occurred after $7 \mathrm{~m}$ and continued to $25 \mathrm{~m}$ (the terminal ileum). It is not possible to say with certainty whether the net disappearance of peptide amino acid was due to intact absorption of peptides into the gut mucosa or to lumen hydrolysis into amino acids, however, these observations are consistent with the results of the present and other studies with non-ruminants. Considerable proportions of digested protein are taken up into the gut mucosa before hydrolysis to free amino acids either at the brush-border or, in the case of short-chain peptides, within the cytoplasm of the enterocytes. Peptides are absorbed faster than their constituent amino acids and the maximal absorption of peptides is generally earlier in the digestive tract than for free amino acids (Nixon \& Mawer, 1970 a, b; Silk et al., 1973). It is noteworthy that in the present study the peptidase activity rose to a maximum in the first two-thirds of the digestive tract, the region in which the greatest net disappearance of peptide nitrogen had been shown to occur in the studies of Ben-Ghedalia et al. (1974).

\section{REFEREN CES}

Adibi, S. A. (1971). Journal of Clinical Investigation 50, 2266-2275.

Baumrucker, C. R. \& Davis, C. L. (1980). Journal of Dairy Science 63, 379-384.

Ben-Ghedalia, D., Tagari, H., Bondi, A. \& Tadmor, A. (1974). British Journal of Nutrition 31, $125-142$.

Das, M. \& Radhakrishnan, A. N. (1973). Biochemical Journal 135, 609-615.

Das, M. \& Radhakrishnan, A. N. (1974). Clinical Science and Molecular Medicine 46, 501-510.

Dixon, M. \& Webb, E. C. (1964). Enzymes, 2nd ed. London: Longmans.

Dolly, J. O., Dillon, A., Duffy, M. J. \& Fottrell, P. F. (1971). Clinica Chimica Acta 31, 55-62.

Duomeng, C. \& Maroux, S. (1979). Biochemical Journal 177, 801-808.

Fujita, M., Parsons, D. S. \& Wojnarowska, F. (1972). Journal of Physiology 227, 377-394.

Heizer, W. D., Kerley, R. L. \& Isselbacher, K. J. (1972). Biochimica et Biophysica Acta 264, 450-461.

Johns, J. T. \& Bergen, W. G. (1973). Journal of Nutrition 103, 1581-1586.

Josefsson, L. \& Lindberg, T. (1965). Biochimica et Biophysica Acta 105, 162-166.

Kim, Y. S., Birtwhistle, W. \& Kim, Y. W. (1972). Journal of Clinical Investigation 51, 1419-1430.

McAllan, A. B. (1981). British Journal of Nutrition 46, 431-440.

McCarthy, D. M. \& Kim, Y. S. (1973). Journal of Clinical Investigation 52, 942-951.

Mathews, D. M. (1975). Physiological Reviews 55, 537-608.

Miller, G. L. (1959). Analytical Chemistry 31, 964.

Nicholson, J. A. \& Kim, Y. S. (1975). Analytical Biochemistry 63, 110-117.

Nicholson, J. A. \& Peters, T. J. (1979). European Journal of Clinical Investigation 9, 349-354.

Nixon, S. E. \& Mawer, G. E. (1970a). British Journal of Nutrition 24, 227-240.

Nixon, S. E. \& Mawer, G. E. (1970b). British Journal of Nutrition 24, 241-258.

Peters, T. J. (1970). Biochemical Journal 120, 195-203.

Philips, W. A., Webb, K. E. Jr \& Fontenot, J. P. (1976). Journal of Animal Science 42, 201-207.

Robinson, G. B. \& Shaw, B. (1960). Biochemical Journal 77, 351-356. 
Silk, D. B. A., Mars, T. C., Addison, J. M., Burston, D., Clark, M. L. \& Mathews, D. M. (1973). Clinical Science and Molecular Medicine 45, 715-719.

Sterchi, E. E. \& Woodley, J. F. (1980a). Clinica Chimica Acta 102, 49-56.

Sterchi, E. E. \& Woodley, J. F. (1980 b). Clinica Chimica Acta 102, 57-65.

Symons, L. E. A. \& Jones, W. O. (1966). Comparative Biochemistry and Physiology 18, 71-82.

Tagari, H. \& Bergman, E. N. (1978). Journal of Nutrition 108, 790-803.

Wahle, K. W. J., Weekes, T. E. C. \& Sherratt, H. S. A. (1972). Comparative Biochemistry and Physiology 41B, 759-769.

Williams, V. J. (1969). Comparative Biochemistry and Physiology 29, 865-870. 